Check for updates

Cite this: RSC Adv., 2019, 9, 34152

Received 6th August 2019

Accepted 10th October 2019

DOI: 10.1039/c9ra06091j

rsc.li/rsc-advances

\section{Alternative electrodes for HTMs and noble-metal- free perovskite solar cells: 2D MXenes electrodes $\uparrow$}

\author{
Junmei Cao, ${ }^{a}$ Fanning Meng, ${ }^{a}$ Liguo Gao, (D) *a Shuzhang Yang, ${ }^{b}$ Yeling Yan, ${ }^{2}$ \\ Ning Wang, ${ }^{a}$ Anmin Liu, ${ }^{a}$ Yanqiang $\mathrm{Li}^{\mathrm{a}}$ and Tingli Ma*b
}

The high cost of hole transporting materials (HTMs) and noble metal electrodes limits the application of perovskite solar cells (PSCs). Carbon materials have been commonly utilized for HTMs and noble-metalfree PSCs. In this paper, a more conductive 2D MXene material $\left(\mathrm{Ti}_{3} \mathrm{C}_{2}\right)$, showing a similar energy level to carbon materials, has been used as a back electrode in HTMs and noble-metal-free PSCs for the first time. Seamless interfacial contact between the perovskite layer and $\mathrm{Ti}_{3} \mathrm{C}_{2}$ material was obtained using a simple hot-pressing method. After the adjustment of key parameters, the PSCs based on the $\mathrm{Ti}_{3} \mathrm{C}_{2}$ electrode show more stability and higher power conversion efficiencies (PCE) $(13.83 \%$, 27\% higher than that $(10.87 \%)$ of the PSCs based on carbon electrodes) due to the higher conductivity and seamless interfacial contact of the MXene electrode. Our work proposes a promising future application for MXene and also a good electrode candidate for HTM and the noble-metal-free PSCs.

\section{Introduction}

2D materials have excellent electronic, mechanical and optical properties, which have attracted much attention since the discovery of graphene monolayers in 2004., ${ }^{\mathbf{1 , 2}}$ Recently, an additional 2D material, early transition metal carbide $\left(\mathrm{Ti}_{3} \mathrm{C}_{2}\right)$, was synthesized by selectively etching the $\mathrm{Al}$ atoms in a layered hexagonal ternary carbide $\left(\mathrm{Ti}_{3} \mathrm{AlC}_{2}\right)$ using aqueous hydrofluoric acid (HF). ${ }^{3} \mathrm{Ti}_{3} \mathrm{C}_{2}$ is one of more than 70 different known transition metal carbides, carbonitrides and nitrides called MXenes. The general formula of MXenes is $\mathrm{M}_{n+1} \mathrm{X}_{n} \mathrm{~T}_{x}(n=1-3)$, where $\mathrm{M}$ is an early transition metal (such as $\mathrm{Sc}, \mathrm{Ti}, \mathrm{Zr}, \mathrm{Hf}, \mathrm{V}, \mathrm{Nb}, \mathrm{Ta}, \mathrm{Cr}$, Mo and others), $\mathrm{X}$ is $\mathrm{C}$ and/or $\mathrm{N}$, and $\mathrm{T}_{x}$ stands for the surface terminations (hydroxyl, oxygen or fluorine). ${ }^{4}$ Various assynthesized MXenes are endowed with excellent properties, such as good electronic conductivity, ${ }^{5}$ high hydrophilicity, ${ }^{6}$ highly transparent ${ }^{7}$ and convenient building blocks. ${ }^{8}$

The versatile chemistry of the MXenes allows the tuning of properties for applications including anti-friction properties, ${ }^{\mathbf{9}}$ electromagnetic interference shielding, ${ }^{\mathbf{1 0}}$ water purification, ${ }^{\mathbf{1 1 , 1 2}}$ nanofiltration, ${ }^{\mathbf{1 3}}$ dye adsorption, ${ }^{\mathbf{1 4}} \mathrm{O}_{2}$ evolution electrocatalysis, ${ }^{15} \mathrm{H}_{2}$ generation, ${ }^{16}$ sensors, ${ }^{17,18} \mathrm{CO}$ catalysis, ${ }^{19} \mathrm{~N}_{2}$ capture and $\mathrm{NH}_{3}$ production, ${ }^{20}$ antibacterial activity, ${ }^{21}$

${ }^{a}$ State Key Laboratory of Fine Chemicals, School of Petroleum and Chemical Engineering, Dalian University of Technology, Panjin, 124221, P. R. China. E-mail: liguo.gao@dlut.edu.cn

${ }^{b}$ Graduate School of Life Science and Systems Engineering, Kyushu Institute of Technology, Kitakyushu, Fukuoka 808-0196, Japan. E-mail: tinglima@life.kyutech. ac.jp

$\dagger$ Electronic supplementary information (ESI) available. See DOI: 10.1039/c9ra06091j electronics ${ }^{22}$ and lubrication. ${ }^{23}$ In our previous report, $\mathrm{Ni}_{2}$ $\mathrm{CO}_{3}(\mathrm{OH})_{2}$ nanosheets and/or nanoparticles were grown in situ on the surface of $\mathrm{Ti}_{3} \mathrm{C}_{2}$ to form a composite electrode, which possessed good supercapacitor properties. ${ }^{24}$

Organic and inorganic lead halide PSCs have shown remarkable development and prospective applications due to their unique advantages, such as high absorption coefficients, excellent carrier transport, low cost, tunable compositions, and excellent structures, thereby allowing simple fabrication by various processes. $^{25-28}$ Although recent studies showed that the PCE of PSCs could achieve $23.7 \%,{ }^{29}$ HTMs (Spiro-OMeTAD commonly used) and noble metal electrode ( $\mathrm{Au}$ and $\mathrm{Ag}$ ) materials are expensive and not beneficial to commercial applications. To solve this problem, researchers have developed HTM and noble-metalfree PSCs. ${ }^{30,37}$ In particular, the utilization of a carbon electrode in such devices has attracted a lot of attention. ${ }^{31}$ We used a super low-cost, coal-based carbon electrode in HTM and noble-metalfree PSCs and obtained a PCE of PSCs at $10.87 \%$, where the PSCs fabricated with a coal-based carbon electrode exhibited more stability than conventional devices. ${ }^{32}$ However, the PCE of HTM and noble-metal-free PSCs is still lower than that of conventional devices. Due to its high conductivity and mobility, $\mathrm{Ti}_{3} \mathrm{C}_{2}$ materials provide a promising future for further improvements in the PCE of HTM and noble-metal-free PSCs. In our previous report, $\mathrm{Ti}_{3} \mathrm{C}_{2}$ was used as an additive incorporated into a perovskite absorber layer. A $2 \%$ enhancement in the device performance was achieved from the incorporation of a $0.03 \mathrm{wt} \%$ amount of $\mathrm{Ti}_{3} \mathrm{C}_{2}$, where $\mathrm{Ti}_{3} \mathrm{C}_{2}$ accelerated the charge transfer due to its high electrical conductivity and mobility. ${ }^{33}$ However, as a new emerging 2D material similar to graphene, the application of MXene in the field of PSCs is still short of intensive study. 
In this paper, HTM and noble-metal-free PSCs have been fabricated with a $2 \mathrm{D} \mathrm{Ti}_{3} \mathrm{C}_{2}$ electrode for the first time. A hotpressing method was carried out for forming a seamless interfacial contact between the perovskite layer and $\mathrm{Ti}_{3} \mathrm{C}_{2}$ electrode. After optimizing the key parameters, the PCE of the champion device increased to $13.83 \%$. Results show that the devices based on the $\mathrm{Ti}_{3} \mathrm{C}_{2}$ electrodes have good reproducibility and better stability than conventional devices. Our work proposes a promising future application for 2D MXenes and also a good candidate for HTM and noble-metal-free PSCs.

\section{Results and discussion}

The $\mathrm{Ti}_{3} \mathrm{C}_{2}$ materials used in this work were prepared by etching $\mathrm{Ti}_{3} \mathrm{AlC}_{2}$ powders in HF solution to form a $\mathrm{Ti}_{3} \mathrm{C}_{2} \mathrm{~T}_{x}$ structure. To illustrate the basic formation process, X-ray diffraction (XRD) and X-ray photoelectron spectroscopy (XPS) were used to characterize the materials, as shown in Fig. 1. The active layer ( $\mathrm{Al})$ can be selectively removed from the interlayers by disconnecting the metallic bonds between $\mathrm{Al}$ and Ti, resulting in $2 \mathrm{D} \mathrm{Ti}_{3} \mathrm{C}_{2}$, as depicted in Fig. 1a. XRD patterns showed that the most notably intense peak at $2 \theta \approx 39^{\circ}$ of $\mathrm{Ti}_{3} \mathrm{AlC}_{2}$ disappeared. Standard peaks of the $\mathrm{Ti}_{3} \mathrm{C}_{2} \mathrm{~T}_{x}$ structure appeared at (002), (004) and (006), where the (002) and (004) peaks were slightly shifted by a small degree due to the enlarged distance of the crystal face of $\mathrm{Ti}_{3} \mathrm{C}_{2} \mathrm{~T}_{x}$ after HF etching: ${ }^{30,34}$ In order to further confirm the elemental distribution, XPS was conducted for $\mathrm{Ti}_{3} \mathrm{C}_{2} \mathrm{~T}_{x}$. From the survey region (Fig. 1b), the signals belonging to the elements $\mathrm{C}, \mathrm{Ti}, \mathrm{O}$ and $\mathrm{F}$ were clearly detected without any signals for $\mathrm{Al}$, which demonstrated that the $\mathrm{Al}$ element had been etched by $\mathrm{HF}$ acid, consistent with the XRD results. In the highresolution XPS spectrum of $\mathrm{Ti} 2 \mathrm{p}$ (shown in Fig. 1c), the components centered at 454.6, 455.6, and $456.6 \mathrm{eV}$ were assigned to $\mathrm{Ti}-\mathrm{C}, \mathrm{Ti}^{2+}$, and $\mathrm{Ti}^{3+}$, respectively. From the $\mathrm{C} 1 \mathrm{~s}$ spectrum, the components fixed at 286.3, 284.3, 281.7, and $281.2 \mathrm{eV}$ were assigned to $\mathrm{C}-\mathrm{O}, \mathrm{C}-\mathrm{C}, \mathrm{C}-\mathrm{H}_{x}$, and $\mathrm{C}-\mathrm{Ti}$, respectively, which is in agreement with previous reports (Fig. 1d). ${ }^{30}$ Therefore, the $2 \mathrm{D} \mathrm{Ti}_{3} \mathrm{C}_{2}$ materials were successfully obtained by HF etching the $\mathrm{Ti}_{3} \mathrm{AlC}_{2}$ powder.

The morphology of $\mathrm{Ti}_{3} \mathrm{AlC}_{2}$ and $\mathrm{Ti}_{3} \mathrm{C}_{2}$ was characterized by a scanning electron microscope (SEM) and transmission electron microscope (TEM), as shown in Fig. 2. $\mathrm{Ti}_{3} \mathrm{AlC}_{2}$ consisted of a number of lamellar grains with densely aligned layered structures (Fig. 2a). After HF etching, exfoliation was achieved and the quasi-2D $\mathrm{Ti}_{3} \mathrm{C}_{2}$ sheets were obtained, as shown in Fig. 2b. The layers in $\mathrm{Ti}_{3} \mathrm{C}_{2}$ were clearly separated from each other in comparison to the unetched $\mathrm{Ti}_{3} \mathrm{AlC}_{2}$ powders, where the opened interspace was formed and the layered structure could be clearly observed. To further investigate the microstructure of the $\mathrm{Ti}_{3} \mathrm{C}_{2}$ nanosheets, TEM was tested as shown in
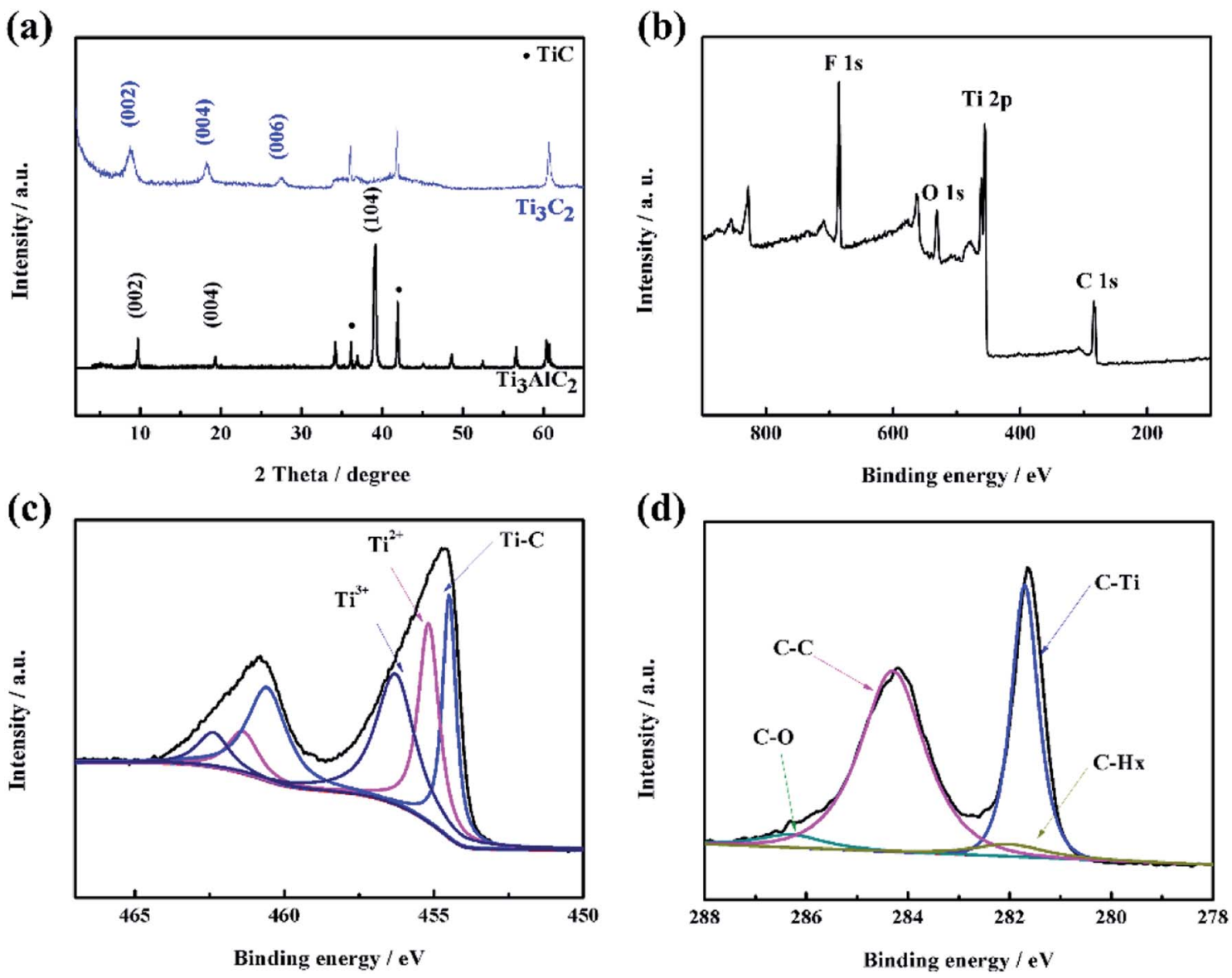

Fig. 1 (a) XRD patterns of $\mathrm{Ti}_{3} \mathrm{AlC}_{2}$ and $\mathrm{Ti}_{3} \mathrm{C}_{2}$. (b) XPS spectra of the $\mathrm{Ti}_{3} \mathrm{C}_{2}$ sample, and the high-resolution spectra of (c) Ti $2 \mathrm{p}$ and (d) $\mathrm{C} 1 \mathrm{~s}$. 
(a)

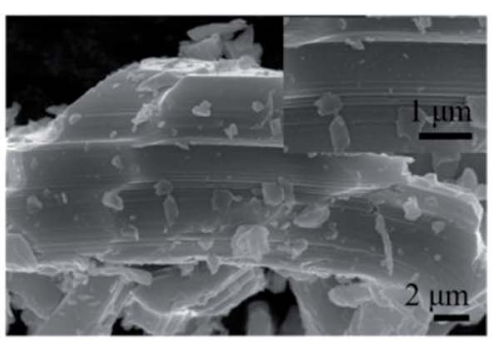

(b)

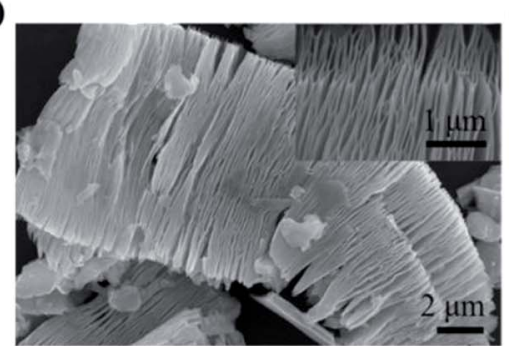

(c)

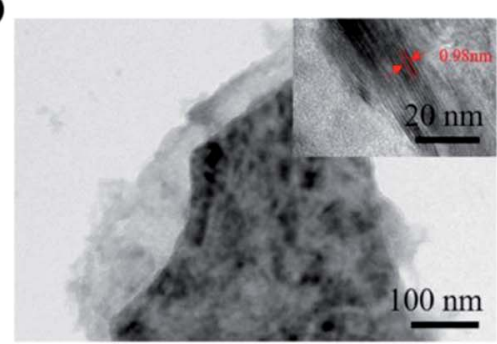

Fig. 2 (a) SEM images of $\mathrm{Ti}_{3} \mathrm{AlC}_{2}$ powder before $\mathrm{HF}$ etching; the inset is an amplified image. (b) $\mathrm{Ti}_{3} \mathrm{C}_{2}$ exfoliation from $\mathrm{HF}$ acid; the inset is an amplified image. (c) TEM image of $\mathrm{Ti}_{3} \mathrm{C}_{2}$ nanosheets exhibiting a stack of multiple layers; the inset is an $\mathrm{HRTEM}$ image of the Ti ${ }_{3} \mathrm{C}_{2}$ nanosheets.

Fig. 2c. The exfoliated $2 \mathrm{D} \mathrm{Ti}{ }_{3} \mathrm{C}_{2}$ nanosheets exhibited a stack of multiple layers. The high-resolution TEM (HRTEM) image (Fig. 2, inset) of the lattice fringe spacing between the two adjacent crystal planes of the nanosheets was determined to be $0.98 \mathrm{~nm}$, which is consistent with the (002) crystal lattice in Fig. 1a.

The cross-sectional SEM image of this HTM and the noblemetal-free PSCs is shown in Fig. 3a, where the layers of FTO, compact $\mathrm{TiO}_{2}$ and mesoporous $\mathrm{TiO}_{2}\left(\mathrm{C} \& \mathrm{M} \mathrm{TiO}{ }_{2}\right), \mathrm{CH}_{3} \mathrm{NH}_{3} \mathrm{PbI}_{3}$, and $\mathrm{Ti}_{3} \mathrm{C}_{2}$ electrode can be clearly differentiated. The $\mathrm{Ti}_{3} \mathrm{C}_{2}$ layer is in a seamless interfacial contact with the perovskite layer, which allows for holes to easily transfer from the light absorption layer to the $\mathrm{Ti}_{3} \mathrm{C}_{2}$ electrode. In order to improve the interfacial contact between the perovskite layer and the electrode materials, the $\mathrm{Ti}_{3} \mathrm{C}_{2}$ materials were ball-milled to form smaller particle sizes, resulting in the morphology change of $\mathrm{Ti}_{3} \mathrm{C}_{2}$. As shown in Fig. $\mathrm{S} 1, \dagger$ the interspaces between the $\mathrm{Ti}_{3} \mathrm{C}_{2}$ layers could not be easily distinguished. Ultraviolet photoelectron spectroscopy (UPS) was conducted to ensure a suitable energy level in $\mathrm{Ti}_{3} \mathrm{C}_{2}$ for the hole extraction, as shown in Fig. S2. $\dagger$ Results show that the work function of the $\mathrm{Ti}_{3} \mathrm{C}_{2}$ material is $4.96 \mathrm{eV}$, which matches well with the valence band of $\mathrm{CH}_{3^{-}}$ $\mathrm{NH}_{3} \mathrm{PbI}_{3}$. The energy-level diagram of the $\mathrm{Ti}_{3} \mathrm{C}_{2}$ electrode-based device is shown in Fig. 3b, where both electrons and holes can be successfully extracted from the $\mathrm{CH}_{3} \mathrm{NH}_{3} \mathrm{PbI}_{3}$ layer. A schematic diagram of the device fabrication is shown in Fig. 3c, where two layers of $\mathrm{Ti}_{3} \mathrm{C}_{2}$ were fabricated. One was prepared by transferring the $\mathrm{Ti}_{3} \mathrm{C}_{2}$ electrode obtained from vacuum (a)

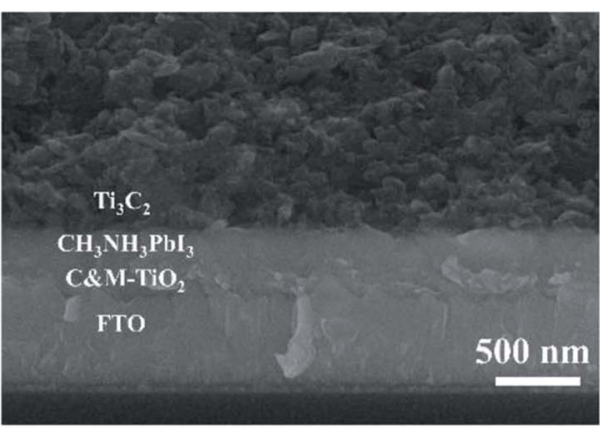

(b)

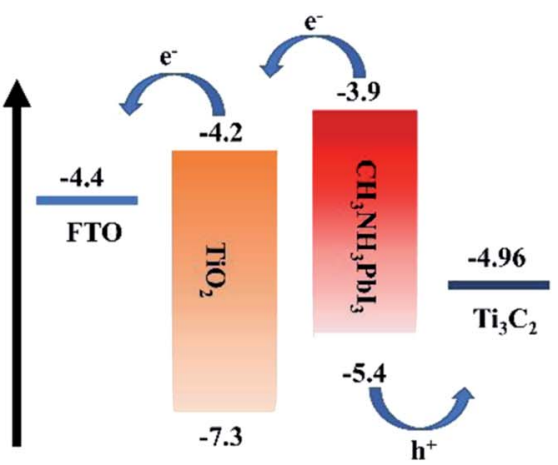

(c)

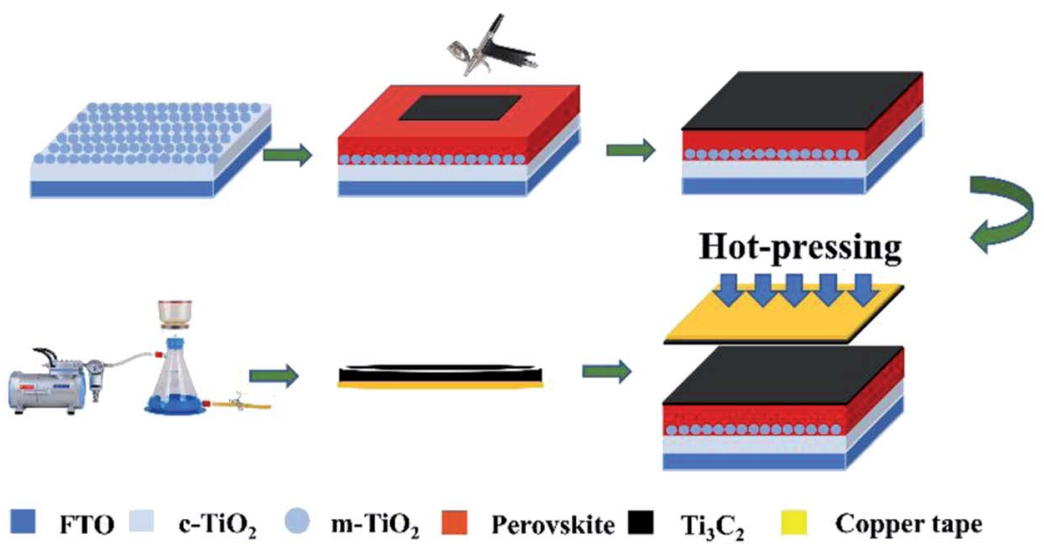

Fig. 3 (a) Cross-sectional SEM image of the PSC based on $\mathrm{Ti}_{3} \mathrm{C}_{2}$ electrode. (b) Energy-level diagram of the PSC. (c) Schematic diagram of the fabrication process of $\mathrm{Ti}_{3} \mathrm{C}_{2}$ electrode by hot-pressing method. 
filtration to the copper tape. The other was prepared by spraying $\mathrm{Ti}_{3} \mathrm{C}_{2}$ paste onto the perovskite layer. To integrate these two $\mathrm{Ti}_{3} \mathrm{C}_{2}$ layers and induce a seamless interfacial contact at the perovskite layer $/ \mathrm{Ti}_{3} \mathrm{C}_{2}$ electrode, the hot-pressing method was used at $85{ }^{\circ} \mathrm{C}$ and $0.4 \mathrm{MPa}$. Because of the thermoplasticity of polyvinyl acetate (PVAc), the prepared $\mathrm{Ti}_{3} \mathrm{C}_{2}$ electrode was tightly connected with the perovskite layer, and the two $\mathrm{Ti}_{3} \mathrm{C}_{2}$ layers made contact with each other without any interfacial crack, as shown in Fig. 3a.

The key parameters and thickness of the $\mathrm{Ti}_{3} \mathrm{C}_{2}$ electrode were adjusted to achieve the optimal photovoltaic performance for the PSCs. The corresponding current density-voltage $(J-V)$ characteristics of the PSCs are shown in Fig. 4a, and the photovoltaic properties are summarized in Fig. S3. $\dagger$ A fourpoint probe resistivity measurement system was employed to measure the square resistance of the $\mathrm{Ti}_{3} \mathrm{C}_{2}$ electrode, and the results are shown in Fig. S4. $\dagger$ When the thickness of the $\mathrm{Ti}_{3} \mathrm{C}_{2}$ electrodes increased from $280 \mu \mathrm{m}$ to $330 \mu \mathrm{m}$, the square resistance decreased from $30.93 \Omega \square^{-1}$ to $25.34 \Omega \square^{-1}$. Thus, the open-circuit voltage $\left(V_{\text {oc }}\right)$, short-circuit current $\left(J_{\text {sc }}\right)$, and the fill factor (FF) of such devices all increased, as shown in Fig. 4a. To explain this phenomenon, a Nyquist plot was measured under illumination $\left(100 \mathrm{~mW} \mathrm{~cm}^{-2}\right)$ at a bias voltage of $0.60 \mathrm{~V}$, which was measured at a frequency range from $100 \mathrm{mHz}$ to $1 \mathrm{MHz}$ (Fig. 4b). The equivalent circuit is presented in Fig. 5c. The series resistance $\left(R_{\mathrm{S}}\right)$ is related to the external resistance, including wires and substrates, among others. ${ }^{35,36}$ In this work, PSCs based on the $\mathrm{Ti}_{3} \mathrm{C}_{2}$ electrodes were provided with similar $R_{\mathrm{S}}$ values (Fig. $4 \mathrm{~b}$ ). Under the premise of the same experimental conditions, except the thickness of the $\mathrm{Ti}_{3} \mathrm{C}_{2}$ electrode, the arc at high frequency is attributed to the charge transport resistance in the devices $\left(R_{\mathrm{tr}}\right)$, which reflects the hole extraction and transport properties associated with the perovskite $/ \mathrm{Ti}_{3} \mathrm{C}_{2}$ electrode interface. The decreased $R_{\text {tr }}$ means that the hole could be extracted more efficiently as the thickness increased from 280 $\mu \mathrm{m}$ to $330 \mu \mathrm{m}$. However, a continuous increase in the thickness of the $\mathrm{Ti}_{3} \mathrm{C}_{2}$ electrodes would cause increasing resistance, and then induce a decline in the photovoltaic performance for the PSCs. It is presumed that when the thickness of the electrode is large, the transport distance and lifetime of the carrier are limited, resulting in a recombination of the electrons and holes.
For further improvement in the performance of the PSC, a small amount of acetylene black was added to the $\mathrm{Ti}_{3} \mathrm{C}_{2}$ electrode. As shown in Fig. S5, $\uparrow$ small acetylene black particles could fill the gaps of the large $\mathrm{Ti}_{3} \mathrm{C}_{2}$ particles for the holes to be extracted and transported efficiently. The optimal ratio of $\mathrm{Ti}_{3} \mathrm{C}_{2}$ to acetylene black was $5: 1$. The corresponding results are shown in Fig. S6 and S7. $\dagger$ In addition, PVAc as a binder played an important role in the performance of the devices. The optimal mass ratio of $\mathrm{Ti}_{3} \mathrm{C}_{2}$ to PVAc was $5: 1$, as well. The $J-V$ curves and photovoltaic parameters of the devices with different ratios of $\mathrm{Ti}_{3} \mathrm{C}_{2}$ to PVAc are shown in Fig. S8 and S9. $\dagger$

Fig. 5a depicts the photovoltaic performance of the champion device $\left(\mathrm{FTO} / \mathrm{C} \& \mathrm{M} \mathrm{TiO}{ }_{2} /\right.$ perovskite $\left./ \mathrm{Ti}_{3} \mathrm{C}_{2}\right)$, where the highest PCE was $13.83 \%$ with a $V_{\text {oc }}$ value of $0.95 \mathrm{~V}, J_{\mathrm{sc}}$ value of 22.97 $\mathrm{mA} \mathrm{cm}{ }^{-2}$, and $\mathrm{FF}$ value of 0.63 . The corresponding incident photon-to-electron conversion efficiency (IPCE) spectrum is shown in Fig. 5b. A high IPCE exceeding $80 \%$ was obtained in the wavelength window ranging from $400 \mathrm{~nm}$ to $750 \mathrm{~nm}$, suggesting that most of the harvested photons in this range could be converted into electrical energy. One important aspect of PSC research and development is manufacturability (production capacity and yields) without large batch-to-batch variations. The results demonstrated that the fabrication of PSCs based on $\mathrm{Ti}_{3} \mathrm{C}_{2}$ electrodes has good reproducibility, as shown in Fig. 5c. The long-term stability results in Fig. $5 d$ shows that the devices based on the $\mathrm{Ti}_{3} \mathrm{C}_{2}$ electrodes were more stable than conventional PSCs (FTO/C\&M $\quad \mathrm{TiO}_{2} /$ Perovskite/Spiro-OMeTAD/Au), especially when the devices were stored at ambient atmosphere and room temperature (humidity 30\%) without any encapsulation for $360 \mathrm{~h}$. Evidently, the PSCs based on the $\mathrm{Ti}_{3} \mathrm{C}_{2}$ electrodes exhibited excellent stability, where $\mathrm{Ti}_{3} \mathrm{C}_{2}$ (about 300 $\mu \mathrm{m})$ could act as an encapsulating layer, resulting in the isolation of air and water.

The PCE of the $\mathrm{Ti}_{3} \mathrm{C}_{2}$ electrode-based PSCs was lower than that of the conventional PSCs. To investigate the possible reason, photoluminescence (PL) spectra were obtained (Fig. S10†). The PL intensity of the perovskite covered with $\mathrm{Ti}_{3} \mathrm{C}_{2}$ film was higher than that of the perovskite coated with Spiro-OMeTAD and Au films, which demonstrates the significant non-radioactive recombination of most carriers at the perovskite/MXene electrode interface. This phenomenon,

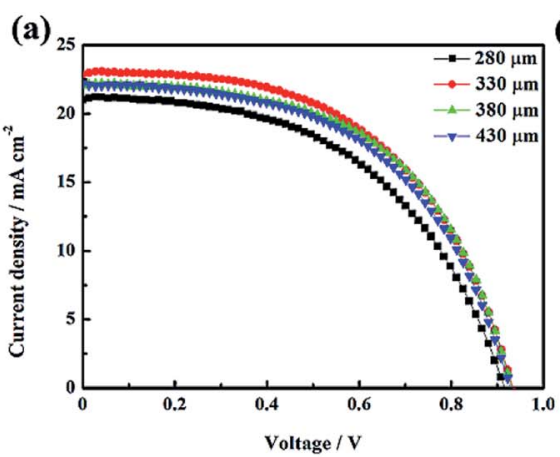

(b)

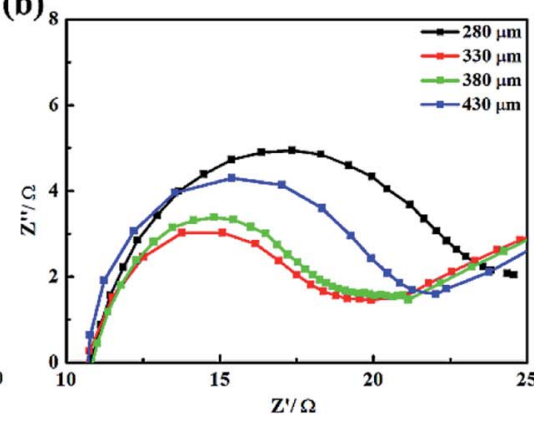

(c)

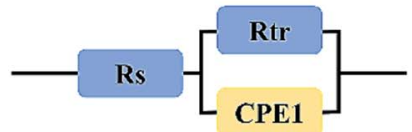

Fig. 4 (a) J-V curves of devices with different thicknesses of the $\mathrm{Ti}_{3} \mathrm{C}_{2}$ electrode. (b) The Nyquist plot was measured under illumination (100 mW $\mathrm{cm}^{-2}$ ) at a bias voltage of $0.60 \mathrm{~V}$. The frequency range is from $100 \mathrm{mHz}$ to $1 \mathrm{MHz}$. (c) Equivalent circuit for fitting the Nyquist curve. 
(a)

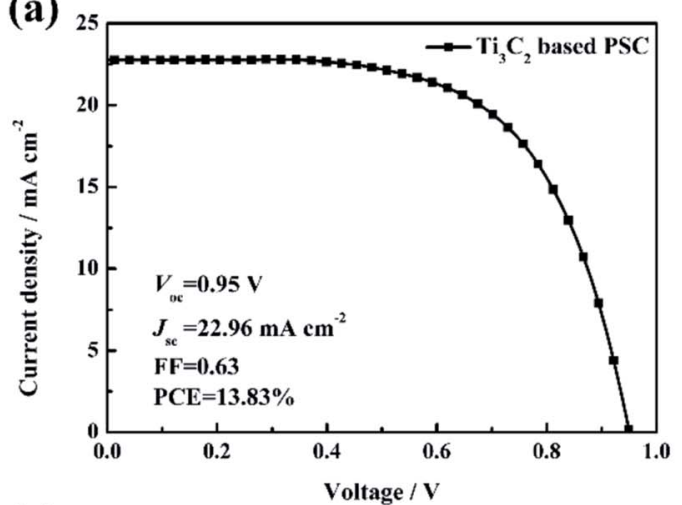

(c)

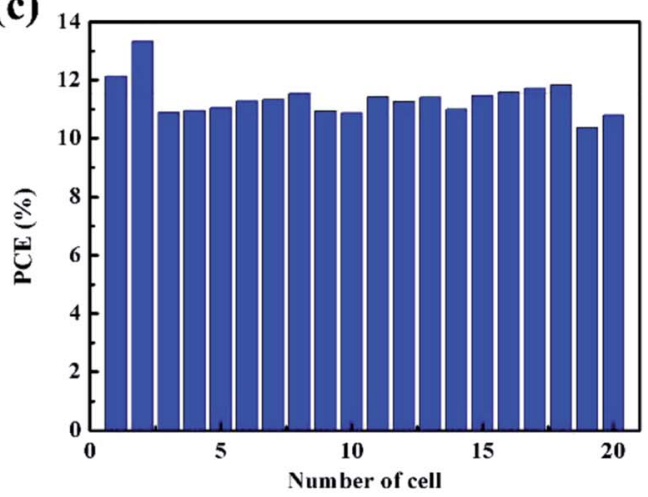

(b)

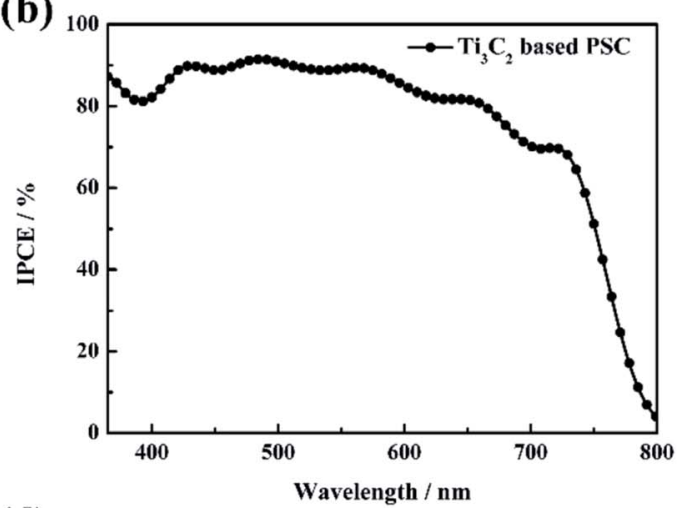

(d)

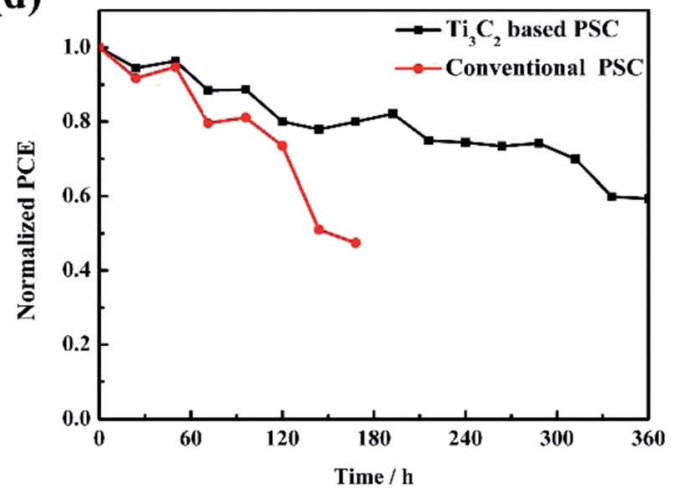

Fig. 5 (a) J-V curves of the champion device based on the $\mathrm{Ti}_{3} \mathrm{C}_{2}$ electrode. (b) IPCE of the champion device. (c) PCE histogram of the PSCs obtained from the measurements of 20 devices. (d) Stability tests of the $\mathrm{Ti}_{3} \mathrm{C}_{2}$ electrode-based PSCs and conventional PSCs in an ambient atmosphere at room temperature (humidity $30 \%$ ).

similar to the carbon electrode, could attribute to a bad contact at the perovskite $/ \mathrm{Ti}_{3} \mathrm{C}_{2}$ electrode interface, which arises from the bulk physics properties of the $\mathrm{Ti}_{3} \mathrm{C}_{2}$ materials. ${ }^{32}$ However, the excellent electrical properties of $\mathrm{Ti}_{3} \mathrm{C}_{2}$ as an electrode material were compared with the coal-based carbon electrode. As shown in Fig. S11, $\dagger$ the photovoltaic performance of PSCs with the $\mathrm{Ti}_{3} \mathrm{C}_{2}$ electrode (denoted as $\mathrm{Ti}_{3} \mathrm{C}_{2}$-based PSCs) was significantly higher than that of PSCs with the coal-based carbon electrode (denoted as coal-based PSCs). This conclusion is because the $\mathrm{Ti}_{3} \mathrm{C}_{2}$ electrode exhibited better conductivity than the coal-based carbon electrode, as shown in Fig. S12. $\dagger$

\section{Conclusions}

We successfully fabricated seamless interfacial contact $\mathrm{Ti}_{3} \mathrm{C}_{2}$ electrodes for HTM and noble-metal-free PSCs through a hotpressing method. Good reproducibility and better stability than conventional PSCs are demonstrated. After adjusting key parameters of the $\mathrm{Ti}_{3} \mathrm{C}_{2}$ electrode, the champion PCE (13.83\%) of the PSCs based on the $\mathrm{Ti}_{3} \mathrm{C}_{2}$ electrode was obtained, which was much higher than that of the coal-based PSCs. This is because the square resistance of the $\mathrm{Ti}_{3} \mathrm{C}_{2}$ electrode was six times lower than that of the carbon electrode. Our work proposes a promising future application for MXene and also a good candidate for HTM and noble-metal-free electrodes for PSCs.

\section{Experimental section}

\section{Device fabrication}

$1 \mathrm{~g}$ of $\mathrm{Ti}_{3} \mathrm{AlC}_{2}$ was slowly added to $30 \mathrm{~mL}$ of $40 \% \mathrm{wt}$ hydrofluoric acid and then stirred with a magnetic stir bar at $300 \mathrm{rpm}$ for $24 \mathrm{~h}$. The residue was washed with deionized water under centrifugation at $3500 \mathrm{rpm}$ for $5 \mathrm{~min}$. The precipitate was recovered while the supernatant was discarded, and this was repeated several times until the suspension $\mathrm{pH}$ reached a value of 6 . The remaining sediment was collected and dried in the vacuum oven at $60^{\circ} \mathrm{C}$ for $24 \mathrm{~h}$. Then, the $\mathrm{Ti}_{3} \mathrm{C}_{2}$ sample was obtained. The obtained $\mathrm{Ti}_{3} \mathrm{C}_{2}$ particles were ball-milled for $48 \mathrm{~h}$ before use. For the $\mathrm{Ti}_{3} \mathrm{C}_{2}$ electrodes, two layers of $\mathrm{Ti}_{3} \mathrm{C}_{2}$ were prepared. One was prepared by transferring the $\mathrm{Ti}_{3} \mathrm{C}_{2}$ film obtained from vacuum filtration to the copper tape. The other was prepared by spraying $\mathrm{Ti}_{3} \mathrm{C}_{2}$ paste onto the perovskite layer. The optimized components in the $\mathrm{Ti}_{3} \mathrm{C}_{2}$ paste were $0.03 \mathrm{~g}$ MXene powder, $0.006 \mathrm{~g}$ acetylene black, and $0.072 \mathrm{~g}$ PVAc in each milliliter of isopropanol solvent, where PVAc in the paste acted as a binder. The $\mathrm{Ti}_{3} \mathrm{C}_{2}$ paste was sprayed onto the as-prepared photoanode, which was placed on a $90{ }^{\circ} \mathrm{C}$ hot plate. Then, the $\mathrm{Ti}_{3} \mathrm{C}_{2}$ film was hot-pressed on the perovskite at $85{ }^{\circ} \mathrm{C}$ under 0.4 MPa pressure for $15 \mathrm{~s}$. Details of the preparation process for the devices are described in ESI. $\dagger$ 


\section{Conflicts of interest}

There are no conflicts to declare.

\section{Acknowledgements}

This work was financially supported by the National Natural Science Foundation of China (Grant No. 51772039, 21703027, 51273032 and 91333104).

\section{References}

1 K. S. Novoselov, A. K. Geim and S. V. Morozov, Science, 2004, 306, 666-669.

2 B. Anasori, M. R. Lukatskaya and Y. Gogotsi, Nat. Rev. Mater., 2017, 2, 16098.

3 M. Naguib, M. Kurtoglu, V. Presser, J. Lu, J. Niu, M. Heon, L. Hultman, Y. Gogotsi and M. W. Barsoum, Adv. Mater., 2011, 23, 4248-4253.

4 M. Naguib, V. N. Mochalin and M. W. Barsoum, Adv. Mater., 2014, 26, 992-1005.

5 M. Naguib, O. Mashtalir, J. Carle, V. Presser, J. Lu, L. Hultman, Y. Gogotsi and M. W. Barsoum, ACS Nano, 2012, 6, 1322-1331.

6 T. Y. Ma, J. L. Cao, M. Jaroniec and S. Z. Qiao, Angew. Chem., Int. Ed., 2016, 55, 1138-1142.

7 J. Halim, M. R. Lukatskaya, K. M. Cook, J. Lu, C. R. Smith, L. Näslund, S. J. May, L. Hultman, Y. Gogotsi, P. Eklund and M. W. Barsoum, Chem. Mater., 2014, 26, 2374-2381.

8 A. K. Geim and I. V. Grigorieva, Nature, 2013, 499, 419-425.

9 Z. Ling, C. E. Ren, M. Q. Zhao, J. Yang, J. M. Giammarco, J. Qiu, M. W. Barsoum, Y. Gogotsi and J. M. Giammarco, Proc. Natl. Acad. Sci. U. S. A., 2014, 111, 16676-16681.

10 Y. Qing, W. Zhou and F. Luo, Ceram. Int., 2016, 42, 1641216416.

11 G. Zou, J. Guo, Q. Peng, A. Zhou, Q. Zhang and B. Liu, J. Mater. Chem. A, 2015, 4, 489-499.

12 J. Guo, Q. Peng, H. Fu, G. Zou and Q. Zhang, J. Phys. Chem. C, 2015, 119, 20923-20930.

13 X. Wu, H. Lan, J. Zhang, Z. Xiang, J. Wang and J. Liu, J. Membr. Sci., 2016, 515, 175-188.

14 O. Mashtalir, K. M. Cook, V. N. Mochalin, M. Crowe, M. W. Barsoum and Y. Gogotsi, J. Mater. Chem., 2014, 2, 14334-14338.

15 T. Y. Ma, J. L. Cao, M. Jaroniec and S. Z. Qiao, Angew. Chem., 2016, 128, 1150-1154.
16 X. Li, C. Zeng and G. Fan, Int. J. Hydrogen Energy, 2015, 40, 3883-3891.

17 J. Chen, K. Chen, D. Tong, Y. Huang, J. Zhang, J. Xue, Q. Huang and T. Chen, Chem. Commun., 2014, 51, 314-317.

18 B. Xiao, Y. C. Li, X. F. Yu and J. B. Cheng, Sens. Actuators, B, 2016, 235, 103-109.

19 Z. Xu, J. Lei, D. Wu, X. Zhao, J. Yu and Z. Zhen, J. Mater. Chem. A, 2016, 4, 4871-4876.

20 L. M. Azofra, N. Li, D. R. MacFarlane and C. Sun, Energy Environ. Sci., 2016, 9, 2545-2549.

21 K. Rasool, M. Helal, A. Ali, C. E. Ren, Y. Gogotsi and K. Mahmoud, ACS Nano, 2016, 10, 3674-3684.

22 X. Li, Y. Dai, Y. Ma, Q. Liu and B. Huang, Nanotechnology, 2015, 26, 135703.

23 J. Yang, B. Chen, H. Song, H. Tang and C. Li, Cryst. Res. Technol., 2015, 49, 926-932.

24 J. Guo, Y. Zhao, N. Jiang, A. Liu, L. Gao, Y. Li, H. Wang and T. Ma, Electrochim. Acta, 2018, 292, 168-179.

25 G. Hodes, Science, 2013, 342, 317-318.

26 A. Kojima, K. Teshima, Y. Shirai and T. Miyasaka, J. Am. Chem. Soc., 2009, 131, 6050-6051.

27 F. Zhang, W. Shi, J. Luo, N. Pellet, C. Yi, X. Li, X. Zhao, T. J. S. Dennis, X. Li, S. Wang, Y. Xiao, S. M. Zakeeruddin, D. Bi and M. Grätzel, Adv. Mater., 2017, 29, 1606806.

28 F. Zhang, D. Q. Bi, N. Pellet, C. X. Xiao, Z. Li, J. J. Berry, S. M. Zakeeruddin, K. Zhu and M. Grätzel, Energy Environ. Sci., 2018, 11, 3480-3490.

29 https://www.nrel.gov/pv/assets/pdfs/pv-efficiencychart.20190103.pdf.

30 K. Domanski, J. P. Correabaena, N. Mine, M. K. Nazeeruddin, A. Abate, M. Saliba, W. Tress, A. Hagfeldt and M. Grätzel, ACS Nano, 2016, 10, 6306-6314. 31 S. N. Habisreutinger, R. J. Nicholas and H. J. Snaith, Adv. Energy Mater., 2016, 7, 1601839.

32 F. Meng, L. Gao, Y. Yan, J. Cao, N. Wang, T. Wang and T. Ma, Carbon, 2019, 145, 290-296.

33 Z. Guo, L. Gao, Z. Xu, S. Teo, C. Zhang, Y. Kamata, S. Hayase and T. Ma, Small, 2018, 14, 1802738.

34 V. M. H. Ng, H. Hui, K. Zhou, P. S. Lee, W. Que, Z. Xu and L. Kong, J. Mater. Chem. A, 2017, 5, 3039-3068.

35 L. Gao, L. Wang, X. Ding, E. Zhao, S. Yang, Y. Zhao, Y. Li, S. Wang and T. Ma, J. Mater. Chem. A, 2018, 6, 4365-4373.

36 S. Yang, X. Song, L. Gao, N. Wang, X. Ding, S. Wang and T. Ma, ACS Appl. Energy Mater., 2018, 1, 4564-4571.

37 F. Meng, A. Liu, L. Gao, J. Cao, Y. Yan, N. Wang, M. Fan, G. Wei and T. Ma, J. Mater. Chem. A, 2019, 7, 8690. 